\title{
LÉONCE NDIKUMANA; JAMES K. BOYCE - AFRICA'S ODIOUS DEBTS: HOW FOREIGN LOANS AND CAPITAL FLIGHT BLED A CONTINENT
}

\author{
Jonathas Martins Nunes ${ }^{1}$
}

Referência da obra resenhada:

NDIKUMANA, L.; BOYCE, James. Africa's odious debts: how foreign loans and capital flight bled a continent. London: Zed Books Ltd, 2011.

Entre as contradições governamentais que assolam os estados emergentes e o oximoro relutante no termo "política pública", em âmbito mundial, estão as que envolvem países com potencial econômico de se tornarem credores externos líquidos afundarem sob o descontrole de suas finanças, corrupção, crises humanitárias massivas, além do aumento da dívida pública, provocadas por propósitos privados desfavoráveis aos interesses socioeconômicos da "nação/população".

As dívidas de todo um continente incorridas pelos regimes políticos, com destinação de recursos estatais para fins improdutivos, ou contrários ao direito internacional, são qualificadas como odiosas, não compulsórias e suscetíveis a repúdio. É nessa conjectura que podemos inscrever o livro Africa's odious debts: how foreign loans and capital flight bled a continent, dos autores Léonce Ndikumana e James K. Boyce, professores de economia na Universidade de Massachusetts, Amherst.

Com base em mais de uma década de pesquisa, os autores apresentam uma análise atualizada e crítica da relação entre empréstimos estrangeiros e fuga de capitais, conferidas a partir de um extenso e fundamentado exame das finanças dos países africanos subsaarianos. Os cinco capítulos que compõem o livro apresentam-se como instâncias elucidativas nas quais as análises dos casos evidenciam um substrato consuetudinário para a prática da dívida odiosa por governantes africanos e seus credores; bem como desconstrói o mito de que a África é um dreno sobre

\footnotetext{
1 Mestrando em Crítica Cultural na Universidade do Estado da Bahia (UNEB), bolsista CAPES, pesquisador do grupo Desleituras em série: da tradução como transcriação, adaptação, refração, diáspora (UNEB). Endereço eletrônico: jonathasmn@gmail.com. Tradutor do livro para esta resenha: Dívidas odiosas da África: Como empréstimos estrangeiros e fuga de capitais sangraram um continente.
} 
as finanças do ocidente, revelando, ao contrário, que o continente é realmente um credor líquido para o resto do mundo.

Com base em métodos estatísticos na análise de exemplos categóricos - o governo do ex-presidente Joseph-Desiré Mobutu, do Zaire (República Democrática do Congo); e o caso de Ferdinand Marcos, das Filipinas - e a partir da conjuntura de estudos empíricos, os autores evidenciam as discrepâncias entre o avanço da dívida, sob empréstimos exteriores exacerbados, e o aumento de ativos em posse dos governantes em bancos internacionais e em paraísos fiscais.

Concomitantemente, ao passo que tais incongruências financeiras são colocadas em evidência, Africa's odious debts transpõe o contexto de degradação social e econômica que se tornara sintomático nesses países, bem como o início de conflitos e gritos por democracia e melhorias dos civis, potencializando o teor da amostragem e análise estatística dos dados ao arrolá-los ao preponderante contexto social decorrente da má administração e desvio de recursos públicos. Circunscritos em tal conjunção, os autores relatam suas experiências enquanto pesquisadores militantes, bem como definem sua escolha por produzir um estudo pautado nas relações políticas de desenvolvimento econômico e social africano - à sombra do zeitgeist dos reclames populares por democracia, advindas dos "ventos do ocidente" ${ }^{2}$ em toda África.

Mesmo ainda no capítulo introdutório, tornam-se precisamente notórias as elucidações sobre o jogo de interesses que alimenta o sistema de desvio de empréstimos estrangeiros e a influência de países do ocidente e de instituições internacionais altamente corruptas na corroboração destes atos. As ponderações sobre os casos da antiga Zaire e das Filipinas - relatadas, vivenciadas e analisadas pelos autores - identificam claramente os sujeitos e as entidades articuladoras na ramificação da dívida pública destes países e da fuga substancial de capitais, tanto criticada ao longo do livro.

No entanto, a partir da leitura das narrativas e correlações estatísticas sobre o acúmulo da dívida externa e a saída de recursos, no decorrer dos cincos capítulos de Africa's odious debts, pode-se inferir que o desvio de empréstimos estrangeiros para a fuga de capitais não é simplesmente uma questão de influência ou crimes, por parte de alguns

${ }^{2}$ Referido no texto supracitado como "Wind from the West". 
governantes e funcionários corruptos, encorajados por alguns banqueiros complacentes ou cúmplices. Mas, é produto de falhas sistêmicas nos arranjos financeiros internacionais que regem os pedidos e empréstimos.

A partir das elucubrações iniciais, fica evidente, no endossamento que ocorre nos capítulos expostos na sequência, a necessidade de levar ao limite os objetivos sinalizados na veia introdutória do livro. No primeiro capítulo - e com o sugestivo título "Tales from the shadows of international finance" - é confrontado o escrutínio de informações que ilustram o papel dos bancos estrangeiros, os quais agem com dupla função no mercado econômico mundial: na posição de credores estatais, teoricamente regido por diretrizes a serem seguidas, e, enquanto veículos de desvio de empréstimos para locais seguros, ou contas particulares. Logo, o que se observa é que, nas sombras das finanças internacionais, grandes somas de valores deslizam por fronteiras, sob a superfície das transações oficialmente registradas e muito além do que é mencionado no arcabouço teórico padrão de livros introdutórios de economia.

Para entender as múltiplas realidades do desenvolvimento e subdesenvolvimento africano, os autores sugerem perscrutar as sombras do sistema financeiro de empréstimos - as quais constituem a desordem de problemas sociais, econômicos e culturais do continente africano. Com efeito, é feito o exame dos empréstimos estrangeiros na África - em paralelo com os "empréstimos mentirosos" nos mercados hipotecários dos EUA que precipitaram o colapso financeiro de 2008 - levantando documentos e números oficiais perante a magnitude das transferências líquidas negativas, as quais ocorrem quando os pagamentos do serviço da dívida por países africanos superam o ingresso de novos empréstimos. O paralelo proposto, contribui ainda para a crítica em relação a influência dos Estados Unidos sobre empréstimos realizados no FMI, evidenciando o crivo ideológico e relações de poder das dívidas mundiais.

O capítulo seguinte, denominado "Measuring African capital flight", é uma perscrutação estatística, necessária para medir a fuga de capitais e dispor de evidências que comprovem a afirmativa crucial dentre as inúmeras contribuições do texto: os países subsaarianos seriam credores líquidos para o resto do mundo, já que, segundo os autores, os ativos externos destes países excedem suas dívidas internacionais. No entanto, apesar de comprovado o superávit, com relação ao montante das dívidas externas, tal exegese 
apontada pelos autores traz à tona a problemática sobre os valores líquidos enviados ao exterior, desvelando a adversidade na detenção dos ativos, isto é, os ativos são privados, enquanto os depósitos são públicos.

A principal diferença entre os dois casos apontados é que boa parte dos ativos estão nas mãos de particulares, isentos de impostos sobre movimentações financeiras, enquanto as dívidas são públicas, tornando uma responsabilidade que foi herdada de governo a governo para os povos africanos. Por conseguinte, a crítica ferrenha da detenção dos ativos apresenta o contrassenso da falta de transparência e documentos relacionados aos números da dívida odiosa, bem como a restrição ao acesso de dados que são de interesse nacional, para manutenção de capitais e futura resolução ou expurgação da dívida.

Perante a complexidade da medição da fuga de capital, os autores elaboram um trabalho estatístico investigativo bastante sofisticado, incluindo, na compilação de dados, a crítica e a análise dos fundos que são adquiridos ilegalmente, e/ou canalizados no exterior de forma ilegal, os quais não são incluídos nas contas oficiais dos países africanos. Com efeito, a referida seção chama ainda a atenção para as implicações das funções metodológicas estatísticas na amostragem dos dados, pois as identidades dos detentores de ativos são, por muitas vezes, ocultas por meio de proxies e vias legais disponíveis nas jurisdições de sigilo bancário. No entanto, os pesquisadores demonstram, ao analisarem e descrevem os métodos utilizados ao decorrer do livro, os progressos substanciais no desenvolvimento de formas de estimar a magnitude da fuga de capitais, sob o cálculo do capital enquanto restante de dinheiro perdido.

O mote do capítulo sobre a movimentação de capitais através de fronteiras internacionais, intitulado "The revolving door", examina os vínculos entre os empréstimos estrangeiros e seu estorno, apresentando evidências quantitativas de que grande parte da fuga de capitais da África subsaariana foi alimentada por dívidas, isto é, os empréstimos de credores estrangeiros ao governo africano, liquidados como ativos privados e detidos em contas de pessoas físicas.

Tal fato é caracterizado ao longo do capítulo como imperativo de “movimentação de valores" ou "porta giratória", em que os valores fluem de credores estrangeiros - impulsionados pelo conforto e perspectiva de resgates de seus empréstimos - e desempenham o fluxo de retorno, voltando para fora 
como fuga de capitais, deste modo, torna-se disponível para a utilização em novos empréstimos.

À primeira vista, tal fenômeno aparenta ser uma prática generalizada em torno do globo, mas, a partir do exame crítico, estatístico e contextual, proposta pelos autores, demonstram-se preocupantes as implicações no desenvolvimento socioeconômico dos países subsaarianos de baixa renda - os quais retêm um valor insignificante em relação as suas demandas, necessitando de incentivos mais efetivos. No entanto, tornar esta possibilidade uma realidade exigirá reformas sistemáticas nas práticas de empréstimos das instituições financeiras, bem como na gestão e uso de recursos externos pelos governos africanos.

Ndikumana e Boyce sugerem uma possível solução sistemática para o problema de extravio de valores e impedimento de aquisição de recursos para desenvolvimento nacional, sob a observação da inutilidade do ato de "puxar o plugue" internacional de empréstimos para países africanos, os autores apontam para a necessidade de conter os vazamentos e corrigir os incentivos perversos que minaram a eficácia dos empréstimos e do auxílio no passado.

Seguindo a crítica sobre os impactos da dívida na população africana, o capítulo 4, "The human costs", documenta a imbricação dos custos humanos com o fenômeno da dívida. Mais uma vez, a análise realizada pelos autores evidencia a relevância de seus resultados e discussões críticas, não apenas para o campo de conhecimento da economia e ciências exatas, mas na esfera de estudos das humanidades. Mesmo embasados em dados estatísticos, Ndikumana e Boyce apresentam, de modo elucidativo, o impacto sociocultural dos pagamentos do serviço da dívida sobre as despesas de saúde pública.

Nos dois primeiros atos da "porta giratória", analisados até então, fica evidente que empréstimos estrangeiros em nome público, bem como no desvio de parte, ou de todo o dinheiro, para ativos privados no exterior, não há perda líquida de capital da África, pois o que vem simplesmente retorna novamente. Contudo, a análise do terceiro e último ato na tragédia da fuga de capitais movimentada pela dívida desvela o grande empecilho no desenvolvimento socioeconômico dos países subsaarianos: a veiculação de parte significativa de suas escassas receitas públicas ao pagamento do serviço da dívida externa. 
Nessa conjuntura, seria obvio se pensar em soluções como maior mobilização de recursos próprios para a melhoria do bem-estar da população; ou exigir que, possíveis doadores, ou credores, providenciem investimentos na saúde e em outras necessidades humanas na África. Mas a outra parte da história, averiguada ao decorrer do livro, se não a mais importante, é a necessidade urgente de encontrar formas para manter os recursos financeiros africanos em seus países e usá-los para sanar toda uma gama de problemas e carência massiva social e política.

Por fim, no último capítulo, "The way forward", os autores apresentam suas conclusões a partir da discussão sobre o que poderia ser feito em relação ao sistema da dívida odiosa nos países subsaarianos. Para tanto, apontam casos para novas políticas e instituições internacionais, baseados na doutrina legal da dívida odiosa à luz da lei internacional, a qual salienta que nesta doutrina tais dívidas seriam consideradas como dívidas pessoais de um regime que nelas incorreu e não dívidas do estado.

Ao final do livro, fica a certeza da relevância do trabalho de Ndikumana e Boyce e sua contribuição para área dos estudos sociais e econômicos, tornando-se vital para qualquer pessoa interessada na África e o futuro de sua relação com o Ocidente. Dentre as contribuições de seus estudos enquanto pesquisadores militantes, as análises em Africa's odious debts implicam diretamente na mudança das estruturas de incentivo na arquitetura financeira internacional, cuja reflexão promova o comportamento responsável por credores e mutuários no futuro.

Apesar da necessidade de uma análise de maior fôlego, no que diz respeito ao quadro comparativo entre diversos países, como os da Ásia e os da América Latina - ao expor que a fuga de capital da África é relativamente menor do que a desses países - a contraposição de dados feitas pelos autores demonstra claramente que o volume de dólares estornados da África para países estrangeiros é maior em relação a proporção da economia africana. No entanto, o ensejo reflexivo proposto ao decorrer das ponderações dos autores avança para a crítica e constatação de que o uso de empréstimos estrangeiros para ganhos privados ilegítimos distorce tanto a política quanto as economias dos países africanos, reforçando o poder das entidades corruptas.

Ademais, em uma época em que a exegese de textos acadêmicos e introdutórios aos estudos econômicos encontram-se cada vez mais condicionados a uma infinidade de abordagens afiliadas a uma miríade de 
LÉONCE NDIKUMANA; JAMES K. BOYCE - AFRICA'S ODIOUS DEBTS: HOW FOREIGN LOANS AND CAPITAL FLIGHT BLED A CONTINENT

agendas políticas da economia, Africa's odious debts acena para a possibilidade de se pensar economia e cultura numa equação mais equilibrada, argumentativa, sem fazer de uma mero objeto da outra.

Recebido em: 01/12/2017

Aprovado em: 18/12/2017 